\title{
Synthesis of Titanium Dioxide Nanoparticles (3nm) by adding PEO
}

\author{
Yatim Lailun Ni'mah ${ }^{(1)}$ and Hwang, Bing Joe ${ }^{(2)}$ \\ (1) Chemistry Department, Faculty of Mathematics and Natural Sciences, Institut Teknologi sepuluh \\ Nopember, Surabaya \\ ${ }^{(2)}$ Chemical Engineering Department, National Taiwan University of Science and technology
}

\begin{abstract}
Nanosized Titanium dioxide $(\mathrm{TiO})$ powder was synthesized via hydrothermal method using titanium tetrachlorida $\left(\mathrm{TiCl}_{4}\right)$ as the precursor and add PEO $(\mathrm{Mw}=600.000)$. The obtained nano powder was used for further characterization. The phase transformation was investigated by an X-ray diffractometer (XRD). The grain size of the TiO2 particle was found to be $3.4 \mathrm{~nm}$. Experimental results have shown that the nano powders have entirely consisted with anatase crystalline phase.
\end{abstract}

KEYWORDS: Titanium dioxide $\left(\mathrm{TiO}_{2}\right)$, nanoparticles, hydrothermal method, X-ray Diffraction.

\section{INTRODUCTION}

Nanoparticles Titanium dioxide $\left(\mathrm{TiO}_{2}\right)$ is a very useful transition metal oxide material and exhibits unique properties such as low cost, easy handling, non-toxicity and resistance to photochemical and chemical erosion. $\mathrm{TiO}_{2}$ also has several potential technological applications in electrochemical energy storage and conversion technology such as sensors, solar cells, photo catalysis, memory devices, fuel cell, and Lithium ion battery [1-5]. These advantages make $\mathrm{TiO}_{2}$ a material in solar cells, chemical sensors, for hydrogen gas evolution, as pigments, self-cleaning surfaces and environmental purification applications [6]. The oxide nanoparticles synthesized by several methods appear more and more useful, because these nanoparticles have good electrical, optical and magnetic properties that are different from their bulk counterparts [7].

Titanium oxide is a semiconducting metal oxide with the band gap of $3.2 \mathrm{eV}$, it can exist in three main crystallographic phases : rutile, anatase, and brookite. It is inexpensive, non-toxic and easily available [16]. The major drawback of titania is its low electronic conductivity, thus the enhancement of the electronic conductivity is desired. Generally, there are two methods to improve titania electronic conductivity, first method is by creating more oxygen vacancy, converting part of the $\mathrm{Ti}^{4+}$ into $\mathrm{Ti}^{3+}$ and the second method is by introducing dopant into titania [17].

$\mathrm{TiO}_{2}$ nanoparticles can be synthesized using various methods such as sulphate process, chloride process, impregnation [8], coprecipitation [9], hydrothermal method [10-12], direct oxidation of $\mathrm{TiCl}_{4}$ [13], metal organic chemical vapor deposition method, etc [14]. Sol-gel method [15] is one of the most convenient ways to synthesize various metal oxides due to low cost, ease of fabrication and low processing temperatures. It is widely used to prepare $\mathrm{TiO}_{2}$ for films, particles or monoliths. In general, the sol gel process involves the transition of a system from a liquid "sol" (mostly colloidal) into a solid "gel" phase. The homogeneity of the gels depends on the solubility of reagents in the solvent, the sequence of addition of reactants, the temperature and the $\mathrm{pH}$. The precursors normally used for the synthesis and doping of nanoparticles are organic alkoxides, acetates or acetylacetonates as well as inorganic salts such as chlorides. Among the classes of solvents, alcohols are largely used but other solvents such as benzene may also be used for some alkoxides. 
In the previous study, $\mathrm{TiO}_{2}$ was synthesized with sol-gel synthesis process and the $\mathrm{TiO}_{2}$ precursor obtained was treated with HMDS vapors at $150^{\circ} \mathrm{C}$ under nitrogen atmosphere to eliminate its surface hydroxyl groups and get the nanoparticle $\mathrm{TiO}_{2}$ with size $40 \mathrm{~nm}$. In this work, the synthesis of $\mathrm{TiO}_{2}$ with hydrothermal process was modified by adding $\mathrm{PEO} . \mathrm{TiO}_{2}$ was synthesized using a hydrothermal method with
PEO being added at an appropriate time (determined by the temperature in the reaction vessel) to inhibit the growth of particle size. The growth of the $\mathrm{TiO}_{2}$ grains was effectively inhibited by the addition of PEO, while aggregation of the treated $\mathrm{TiO}_{2}$ powders could be avoided to result in a better dispersion of the particles. The characterization of particles was carried out by XRD (X Ray Diffraction).

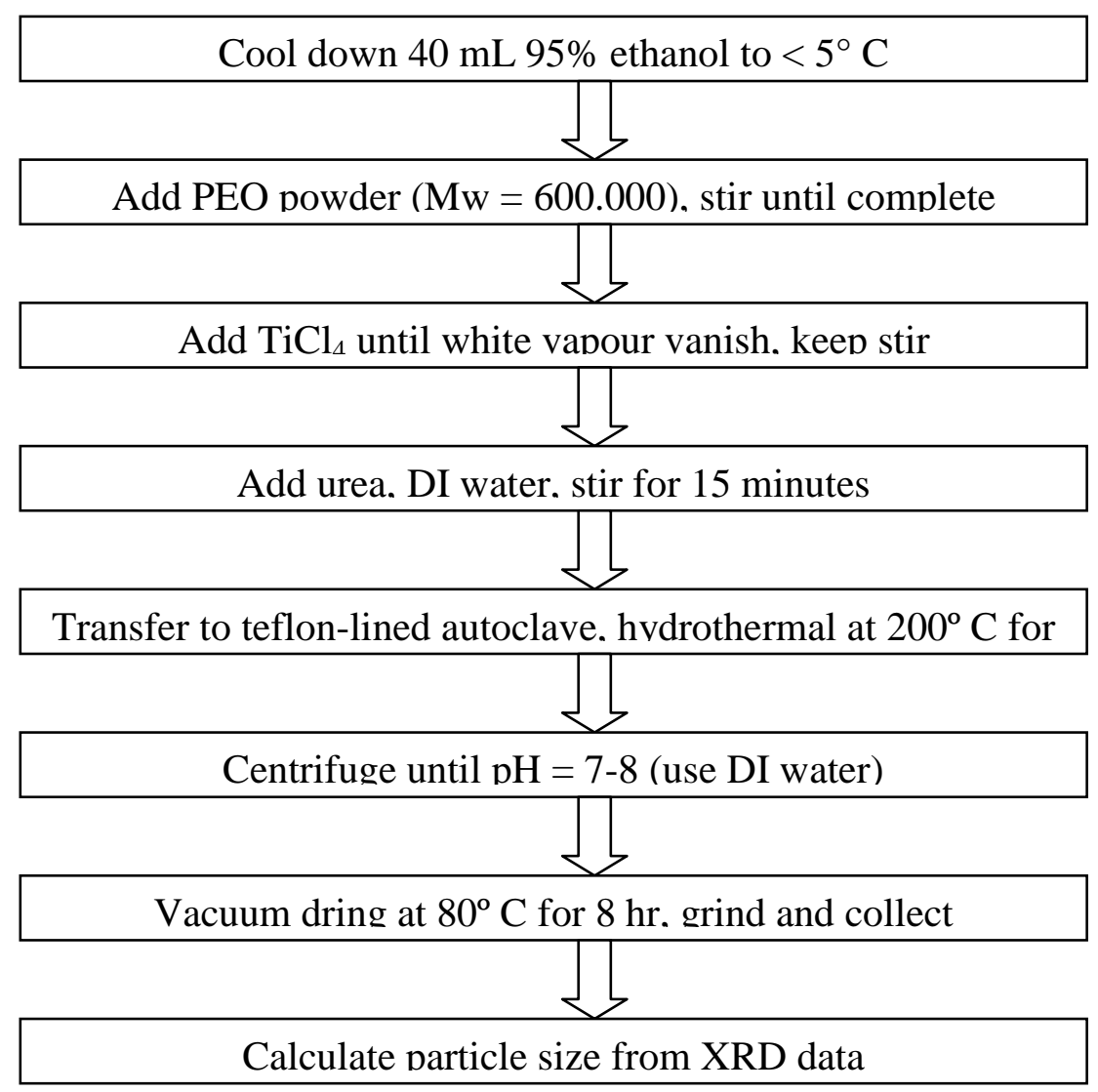

Scheme 1. Synthesis of nano-sized $\mathrm{TiO}_{2}$ powder

\section{PROCEDURE}

\subsection{Materials}

The materials that used in this experiment are Titanium (IV) Chloride $\left[\mathrm{TiCl}_{4}\right.$; MW : 189.91; 99.9\% purity] Acros Organics, Ethyl Alcohol $\left[\mathrm{C}_{2} \mathrm{H}_{5} \mathrm{OH} ; \quad\right.$ MW : 46.07; $99.5 \%$ purity] Shimakyu's Pure Chemicals, Urea $\left[\mathrm{Co}\left(\mathrm{NH}_{2}\right)_{2}\right.$; MW : 60, 99.5\% purity] Acros Organics, Deionized Water (ionic resistance : $18 \mathrm{M} \Omega$ ), Millipore and Poly Ethylene Oxide
$\left[\mathrm{HO}\left(\mathrm{CH}_{2} \mathrm{CH}_{2} \mathrm{O}\right)_{n} \mathrm{H} ; \quad \mathrm{MW} \quad: \quad 600.000\right)$ Acros Organics

\subsection{Synthesize of nano-sized $\mathrm{TiO}_{2}$ powder}

$\mathrm{TiO}_{2}$ powders were prepared by a hydrothermal process. $\mathrm{TiCl}_{4}$ (Acros), DI water, Urea and ethanol (Acros) solvent were mixed, stirred for 15 minutes and kept the temperature $<5{ }^{\circ} \mathrm{C}$. PEO (molecular weight $=600,000)$ was dissolved in ethanol and added to the previous solution and stirred for 15 minutes. The hydrothermal process was conducted at $200{ }^{\circ} \mathrm{C}$, for 2 hours with a 
heating rate of $10{ }^{\circ} \mathrm{C} /$ minute. To separate the product, it was centrifuged and then oven dried under vacuum overnight.

\section{RESULTS AND DISCUSSIONS}

X-Ray Diffraction (XRD), also known as powder diffraction is a technique to characterize the crystallographic structure, crystallite size (grain size) and preferred orientation in polycrystalline samples. XRD is commonly used to identify unknown substances or to determine the purity of crystalline material by comparing diffraction data against a database maintained by the International Centre for Diffraction Data (ICDD).

In this particular study, XRD was used to characterize the crystallinity and the grain size of $\mathrm{Tio}_{2}$. XRD analysis in this study was performed using desktop Bruker D2 Phaser XRD machine with $\mathrm{Cu} \mathrm{K}_{\alpha}$ irradiation as photon source, $\lambda=$ $1.5406 \AA$, Ni filter, $40 \mathrm{kV}$ and $100 \mathrm{~mA}$. All samples was analyze in the range of $2 \theta=20^{\circ}-60^{\circ}$, scanning speed $1 \%$ min and $0.05^{\circ}$ point scanning step.

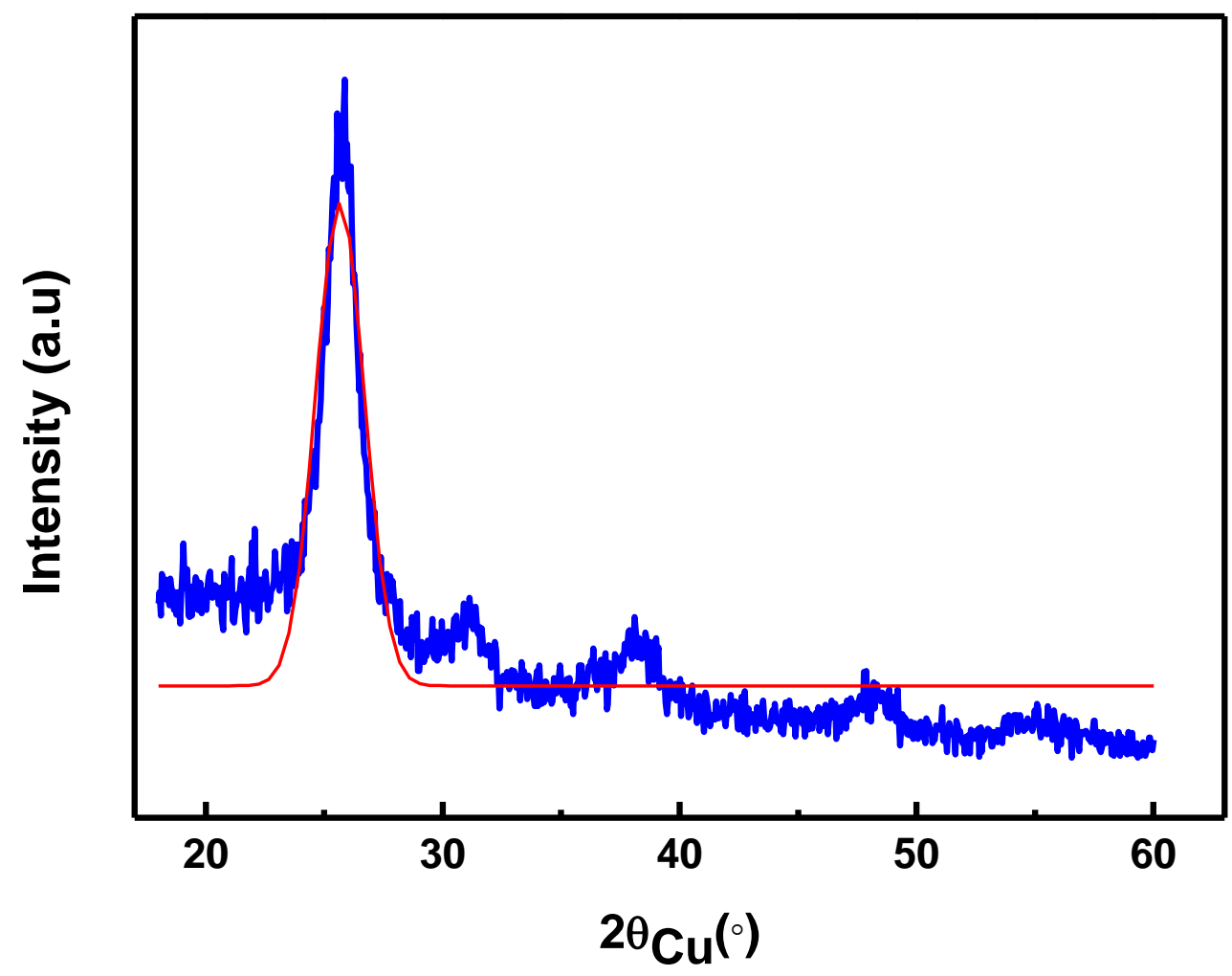

Figure 1. Fitting curve of XRD Pattern for $\mathrm{TiO}_{2}$

Obtained XRD patterns were then compared with JCPDS reference from ICDD. EVA DIFFRAC 2.0 software was used to access JCPDS references. For the crystallite size estimation, Debye-Scherrer equation (eq. 1) was applied.

$$
t=\frac{K \cdot \lambda}{B \cdot \cos \theta}
$$

where :

$\mathrm{K}=$ shape factor (throughout this study $\mathrm{K}=0.9$ ) $\mathrm{t}=$ crystallite size $(\AA)$ $\lambda=$ X-ray wavelength $\left(\mathrm{Cu} \mathrm{K}_{\alpha}=1.5406 \AA\right)$

$\mathrm{B}=$ full width at half height maximum, FWHM

$\theta=$ angle (degree)

The FWHM was estimated by using OriginLab 8.0 software based on the strongest intensity XRD peak, this peak was fitted by using PsigVoigdt1 function.

Figure 1 shows the XRD pattern of nano sized $\mathrm{TiO}_{2}$. The peak appeared at $2 \theta$ value ranging the diffraction peak at $2 \theta$ with $25.3^{\circ}, 38.3^{\circ}, 48^{\circ}, 54^{\circ}$, 
indicate to the formation of anatase phase of $\mathrm{TiO}_{2}$. The phase of nanosized $\mathrm{TiO}_{2}$ is pure anatase phase, agree with our previous result [5]. The smallest particle size after optimazion is $3.4 \mathrm{~nm}$. This smallest particles size due to adding PEO during synthesize process and PEO inhibit the growth of particle size.

The avarage size of the particles was calculated using Debye-Scherrer's formula. By following (1) equation, we can calculate and get the particle size (t) is $3.4 \mathrm{~nm}$.

\section{REFERENCES}

[1] W. Li, S. Ismat Shah, C. P. Huang, O. Jung and C. Ni, Mater. Sci. Eng. B 96, 247, (2002).

[2] J. T. Remillard, J. R. Mc Bride, K. E. Nietering, A. R. Drews and X. Zhang, J. Phys. Chem. B 104, 4440, (2000).

[3] E. Traversa, J. Am. ceram. Soc. 78, 2625, (1995).

[4] A. I. Kingon, J. P. Maris and S. K. Steiffer, Nature (London) 406, 1032, (2000).

[5] Lin, C.W., et al., Influence of TiO2 nano-particles on the transport properties of composite polymer electrolyte for lithium-ion batteries. Journal of Power Sources, 146(1-2): p. 397-401, (2005).

[6] M. R. Hoffmann, S. T. Martin, W. Choi and D. W. Bahnemann, 'Environmental Applications of Semiconductor Photocatalysis", Che. Rev., Vol. 95, No. 1, pp. 69-96, (1995).

[7] H. Xu, X. Wang and I. Zhang, "Selective preparation of nanorods and micro-octahedron of $\mathrm{Fe} 2 \mathrm{O} 3$ and their catalytic performances for Thermal decomposition of Ammonium perchlorate", Powder Technol., Vol. 185, No.2, pp. 176-180, (2008).

[8] Litter, M.I. and J.A. Navio, Comparison of the photocatalytic efficiency of TiO 2, iron oxides and mixed $\mathrm{Ti}$ (IV), Fe (III) oxides: photodegradation of oligocarboxylic acids. Journal of
Photochemistry and Photobiology A: Chemistry, 1994. 84(2): p. 183-193.

[9] Palmisano, L., et al., Activity of chromium-iondoped titania for the dinitrogen photoreduction to ammonia and for the phenol photodegradation. The Journal of Physical Chemistry, 1988. 92(23): p. 6710-6713.

[10] Wang, Y., et al., Preparation, characterization and photoelectrochemical behaviors of $\mathrm{Fe}(I I I)$ doped TiO2 nanoparticles. Journal of Materials Science, 1999. 34(15): p. 3721-3729.

[11] Cheng, H., et al., Hydrothermal preparation of uniform nanosize rutile and anatase particles. Chemistry of Materials, 1995. 7(4): p. 663-671.

[12] Wang, Y., et al., The photoelectrochemistry of transition metal-ion-doped TiO2 nanocrystalline electrodes and higher solar cell conversion efficiency based on Zn2+-doped TiO2 electrode. Journal of Materials Science, 1999. 34(12): p. 2773-2779.

[13] Akhtar, M.K., Y. Xiong, and S.E. Pratsinis, Vapor synthesis of titania powder by titanium tetrachloride oxidation. AIChE Journal, 1991. 37(10): p. 1561-1570.

[14] Li, W., et al., Metallorganic chemical vapor deposition and characterization of $\mathrm{TiO} 2$ nanoparticles. Materials Science and Engineering: B, 2002. 96(3): p. 247-253.

[15] Wang, C.-C., Z. Zhang, and J.Y. Ying, Photocatalytic decomposition of halogenated organics over nanocrystalline titania. Nanostructured Materials, 1997. 9(1-8): p. 583586.

[16] Chen, X. and S.S. Mao, Titanium dioxide nanomaterials: synthesis, properties, modifications, and applications. Chemical reviews, 2007. 107(7): p. 2891-2959.

[17] Leroux, F., et al., Study of the formation of mesoporous titania via a template approach and of subsequent Li insertion. Journal of Materials Chemistry, 2002. 12(11): p. 3245-3253. 